\title{
Perancangan Aplikasi Pembayaran SPP Berbasis Java Desktop Pada SMA Putra Bangsa di Depok
}

\author{
Aditya Karunia Tirto Maulana ${ }^{1}$, Saputra Dwi Nurcahya ${ }^{2}$, dan H. Tom Amrozi ${ }^{3}$ \\ Program Studi Informatika, Fakultas Teknik dan Ilmu Komputer, Universitas Indraprasta PGRI \\ Jalan Raya Tengah No.80, Kelurahan Gedong, Pasar Rebo, Jakarta Timur - 12530 \\ Corresponding author‘s e-mail: aditya.karunia@gmail.com¹, dosen.putra@gmail.com². \\ Tom.dira@gmail.com³
}

\begin{abstract}
Abstrak - Pada era globalisasi ini, aplikasi pengolahan data administrasu telah digunakan oleh banyak pihak, baik organisasi, instansi, maupun lembaga pendidikan. Hal ini dikarenakan, aplikasi pengolahan data administrasi dapat memicu kinerja sebuah instansi menjadi lebih baik dari sebelumnya. Pengolahan data pembayaran SPP di SMA Putra Bangsa di Depok sampai saat ini masih berjalan secara manual, sehingga kegiatan yang berhubungan dengan administrasi masih lambat bahkan harus mengantri untuk melakukan pembayaran. Secara khusus, fungsi yang dilakukan oleh aplikasi administrasi pembayaran yang dikembangkan antara lain pembayaran SPP, penagihan pembayaran, dan pendataan peserta didik. Menampilkan informasi peserta didik, laporan pembayaran SPP. hingga laporan pelunasan. Aplikasi administrasi pembayaran ini dikembangkan dengan menggunakan bahasa pemrograman Java. Dengan adanya sistem pembayaran yang terkomputerisasi ini diharapkan dapat meningkatkan pengolahan data pembayaran SPP serta pembuatan laporan pembayaran dengan lebih efektif dan efisien.

Kata kunci: Aplikasi_Pembayaran, Aplikasi_Pembayaran_SPP, Java_Desktop
\end{abstract}

\section{Pendahuluan}

Dalam era globalisasi dan kemajuan Teknologi Informasi pada saat ini medorong kita untuk selalu up to date dalam sebuah informasi[1]. Penggunaan komputer sebagai salah satu alat teknologi informasi yang sangat dibutuhkan keberadaannya hampir disetiap aspek kehidupan. Tuntutan untuk mengakses sebuah informasi dengan cepat, mendorong kita untuk menciptakan sebuah sarana atau media yang dapat membantu kita dalam mengakses sebuah informasi dengan cepat dan akurat. Menurut Hasan Abdurahman dan Asep Ririh Riswaya (2014), aplikasi adalah program siap pakai yang dapat digunakan untuk menjalankan perintah-perintah dari pengguna aplikasi tersebut dengan tujuan mendapatkan hasil yang lebih akurat sesuai dengan tujuan pembuatanaplikasi tersebut[2]. Aplikasi memiliki arti yaitu pemecahan masalah yang menggunakan salah satu teknik pemrosesan data aplikasi yang biasanya berpacu pada sebuah komputansi yang diinginkan atau diharapkan maupun pemrosesan data yang diharapkan.

Berdasarkan kondisi di atas, maka penulis tertarik untuk mengambil permasalahan yang berjudul: "Perancangan Aplikasi Pembayaran SPP Berbasis Java Desktop pada SMA Putra Bangsa di Depok". Untuk mempermudah proses pendataan pembayaran SPP pada SMA Putra Bangsa yang dilakukan oleh 1 bendahara, dan mempercepat proses laporan yang dibutuhkan sebagai pelengkap kinerja bendahara.

\section{Tinjauan Pustaka}

Tabel tinjauan pustaka merupakan tabel yang dibuat untuk mendefinisikan penelitian yang sebelumnya hampir sama dilakukan dengan penelitian yang diajukan saat ini, adapun perbandingan yang menjadi tabel tinjauan pustaka penelitian yakni dapat dilihat pada tabel 1 .

\begin{tabular}{|c|c|c|c|}
\hline Penulis & Nama Jurnal & Judul Jurnal & Kesimpulan \\
\hline $\begin{array}{l}\text { Sulistiya Dwi Ningsih, } \\
\text { Ani Oktarini Sari, } \\
\text { Eva Zuraidah }\end{array}$ & $\begin{array}{l}\text { Pengembangan } \\
\text { Riset dan Observasi } \\
\text { Sistem Komputer }\end{array}$ & $\begin{array}{l}\text { Implementasi } \\
\text { Aplikasi } \\
\text { Pembayaran } \\
\text { SPP pada TK } \\
\text { Al-Hidayah } \\
\text { Tangerang }\end{array}$ & $\begin{array}{l}\text { Adapun kesimpulan dari jurnal ini } \\
\text { adalah untuk membuat perubahan } \\
\text { atau modifikasi pada sistem yang } \\
\text { telah berjalan dengan mengganti } \\
\text { sistem yang digunakan secara } \\
\text { manual menjadi sistem aplikasi } \\
\text { berbasis java desktop. Aplikasi ini } \\
\text { dapat merekap laporan keuangan } \\
\text { agar lebih efektif tiap bulannya } \\
\text { tanpa harus mencatat nama siswa } \\
\text { secara manual serta mengurangi } \\
\text { adanya kesalahan dalam }\end{array}$ \\
\hline
\end{tabular}




\begin{tabular}{|c|c|c|c|}
\hline & & & pendataan[3]. \\
\hline $\begin{array}{l}\text { Tri Ngudi Wiyatno, } \\
\text { Asep Muhidin, } \\
\text { Novian Dwi Prasetyo }\end{array}$ & $\begin{array}{l}\text { Jurnal Sistem } \\
\text { Informasi dan Ilmu } \\
\text { Komputer Prima }\end{array}$ & $\begin{array}{l}\text { Perancangan } \\
\text { Sistem } \\
\text { Informasi } \\
\text { Pembayaran } \\
\text { SPP Berbasis } \\
\text { Desktop } \\
\text { Menggunalan } \\
\text { Visual Basic }\end{array}$ & $\begin{array}{l}\text { Adapun kesimpulan dari jurnal ini } \\
\text { adalah dengan adanya aplikasi } \\
\text { sistem informasi SPP yang telah } \\
\text { dirancang mampu mengurangi } \\
\text { pekerjaan admin sehingga } \\
\text { dilakukan efisiensi, serta akan } \\
\text { secara otomatis terintegrasi saat } \\
\text { proses pembuatan laporan[4]. }\end{array}$ \\
\hline $\begin{array}{l}\text { Rifki Fajriansyah, } \\
\text { Abdul Mufti, } \\
\text { Alpi Mahisha Nugraha }\end{array}$ & $\begin{array}{lr}\text { Seminar } & \text { Nasional } \\
\text { Riset dan Inovasi } \\
\text { Teknologi }\end{array}$ & $\begin{array}{l}\text { Perancangan } \\
\text { Sistem } \\
\text { Aplikasi } \\
\text { Administrasi } \\
\text { Keuangan } \\
\text { Sekolah pada } \\
\text { SMK Adi } \\
\text { Luhur } 2\end{array}$ & $\begin{array}{l}\text { Adapun kesimpulan dari jurnal ini } \\
\text { adalah dengan adanya aplikasi } \\
\text { administrasi keuangan sekolah, } \\
\text { sistem yang ada mengalami } \\
\text { perubahan yang mana sistem } \\
\text { sudah terkomputerisasi, proses } \\
\text { pengolahan data dapat disimpan di } \\
\text { database, serta pembuatan laporan } \\
\text { dapat dilakukan dengan mudah. } \\
\text { Namun, pengguna perlu } \\
\text { melakukan pelatihan dalam } \\
\text { penggunaan aplikasi ini agar } \\
\text { dalam penggunaan aplikasi ini } \\
\text { tidak terjadi kesalahan pendataan } \\
\text { administrasi keuangan[5]. }\end{array}$ \\
\hline
\end{tabular}

\section{Metode Penelitian}

Penelitian dilaksanakan pada semester ganjil paket X tahun ajaran 2021/2022 yaitu antara awal bulan Oktober 2021 sampai dengan bulan Januari 2022. Penelitian ini bertempat di SMA Putra Bangsa yang berlokasi di Jalan Kedondong No.3, RT.001/RW.015, Kemiri Muka, Kecamatan Beji, Kota Depok, Jawa Barat 16423. Lokasi tersebut dipilih karena berkaitan dengan tempat bekerja dan mempermudah penulis dalam melakukan penelitian.

Penelitian ini dilakukan untuk membuat suatu program aplikasi sistem Pembayaran SPP berbasis Java Dekstop pada SMA Putra Bangsa di Depok. Berikut pembahasan masing-masing tahap dalam penelitian adalah sebagai berikut :

1. Studi Literatur

Pada tahap ini dilakukan pencarian landasan-landasan teori yang diperoleh dari berbagai buku dan juga internet untuk melengkapi perbendaharaan konsep dan teori, sehingga memiliki landasan dan keilmuan yang baik dan sesuai[6].

2. Pengumpulan Data

Pada bagian ini dilakukan proses pengumpulan data dengan metode wawancara dan observasi untuk melakukan pengamatan dan analisa terhadap proses pendataan pembayaran SPP di SMA Putra Bangsa sehingga mendapatkan data dan informasi yang dibutuhkan oleh peneliti[7].

3. Analisis Sistem

Untuk tahap analisis sistem akan dilakukan identifikasi masalah pada sistem yang sedang berjalan. Dengan demikian, diharapkan peneliti dapat menemukan kendala-kendala dan permasalahan yang terjadi pada proses perancangan sistem aplikasi di SMA Putra Bangsa sehingga peneliti dapat mencari solusi dari permasalahan tersebut.

4. Pembuatan Laporan

Pada proses tahapan ini akan dilakukan pembuatan laporan yang disusun menggunakan teknik pengumpulan data primer dan sekunder sehingga menjadi laporan penelitian yang dapat memberikan gambaran secara utuh tentang sistem yang sedang dibangun[8].

Salah satu komponen yang penting dalam penelitian adalah proses peneliti dalam pengumpulan data. Pengumpulan data dilakukan untuk memperoleh informasi yang dibutuhkan dalam rangka mencapai tujuan 
penelitian. Adapun metode pengumpulan data yang digunakan dalam menyelesaikan tugas akhir ini adalah sebagai berikut :

\section{Metode Observasi}

Metode observasi merupakan metode pengumpulan data dengan cara mengamati secara langsung di lapangan. Melalui metode ini peneliti melakukan pengamatan langsung atau survei di SMA Putra Bangsa untuk memperoleh informasi yang benar-benar akurat. Selain itu, metode ini juga berfungsi untuk menambah informasi terhadap kegiatan yang berhubungan dengan masalah yang diangkat. Penulis merupakan salah satu karyawan dari SMA Putra Bangsa, oleh sebab itu penulis sudah mulai memantau atau mengobservasi sebelum kasus covid-19 muncul. Sehingga ketika kasus covid-19 muncul, penulis sudah mendapatkan informasi yang cukup untuk melakukan penelitian ini.

\section{Metode Wawancara}

Metode wawancara digunakan untuk pengumpulan data dengan cara mengajukan berbagai pertanyaan kepada pihak perusahaan. Pertanyaan-pertanyaan tersebut berhubungan dengan proses pembayaran di SMA Putra Bangsa. Metode wawancara dilakukan secara langsung dengan Bendahara di SMA Putra Bangsa.

\section{Metode Pustaka}

Pada metode ini, penulis mempelajari buku-buku yang berhubungan langsung dengan masalah yang dibahas. Selain itu, penulis juga mencari informasi-informasi melalui internet yang berhubungan dengan permasalah yang akan penulis kembangkan. Metode ini sangat membantu dalam mencari informasi yang berkaitan dengan penelitian yang penulis lakukan, sehingga mempercepat selesainya penelitian ini.

\section{Studi Literatur Sejenis}

Studi literatur sejenis merupakan metode pengumpulan data dengan mempelajari penelitian sejenis yang akan dilakukan oleh penulis. Metode ini membantu penulis dalam mendapatkan gambaran tentang solusi dari masalah yang terjadi. Selain itu, penulis dapat mengetahui garis beras proses yang ada pada aplikasi pembayaran SPP.

\section{Hasil dan Pembahasan}

Berisi hasil penelitian dan dapat dilengkapi dengan Aplikasi Pembayaran SPP yang akan menjadi tertulis yang akurat. Untuk mengakses aplikasi ini admin harus memiliki email dan password. Pimpinan hanya dapat melihat hasil dari laporan ini dalam bentuk media cetak yang telah diprint oleh admin dan diminta oleh pimpinan sesuai request.

Aplikasi ini memiliki beberapa batasan dan aturan untuk memudahkan laporan. Bukti pembayaran SPP harus diberikan langsung oleh orang tua/wali peserta didik maupun peserta didik itu sendiri kepada bendara dengan menggunakan bukti pembayarn yang sah, seperti kartu SPP, maupun bukti transfer melalui bank.

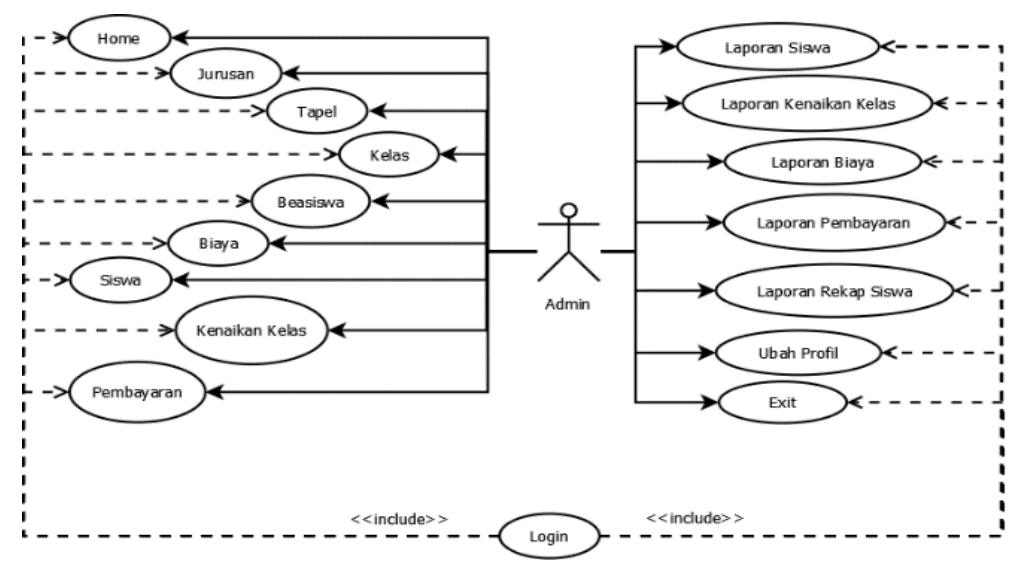

Gambar 1. Use Case Diagram yang Diusulkan 


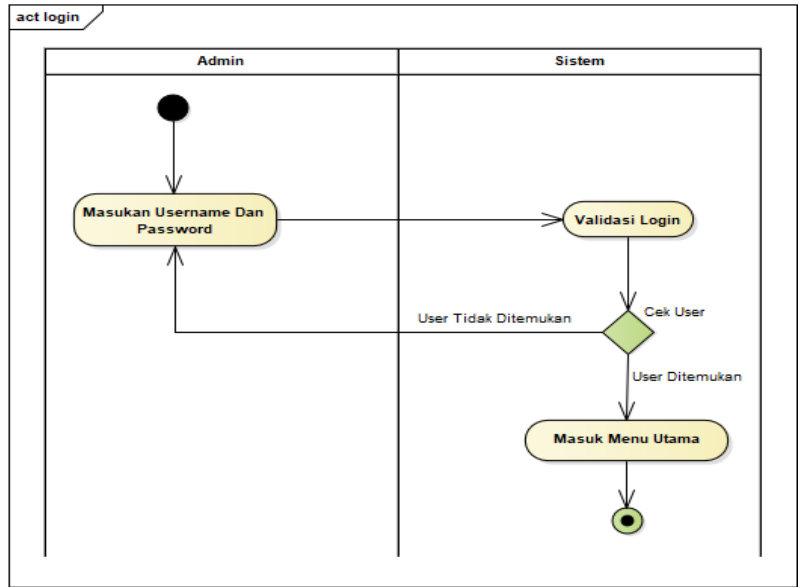

Gambar 2. Activity Diagram Login

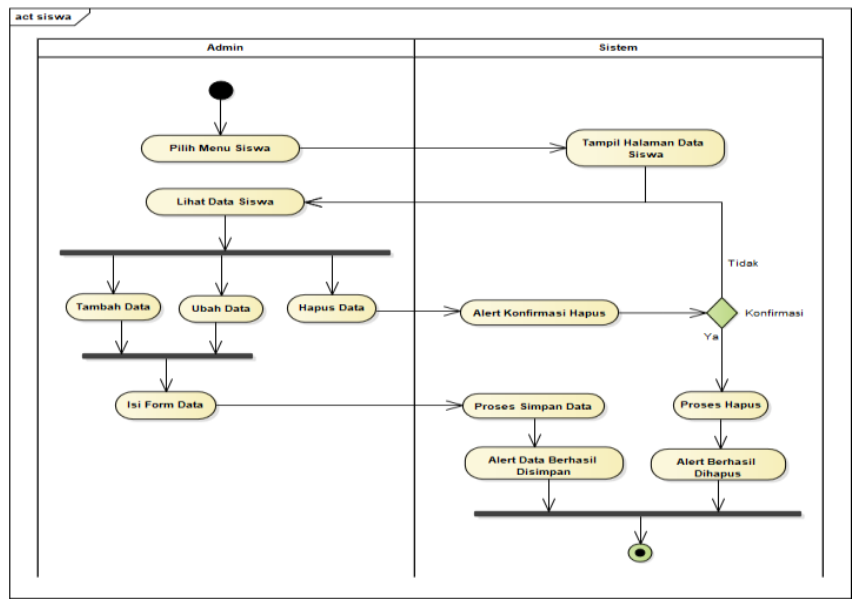

Gambar 3. Activity Diagram Mengelola Data Siswa

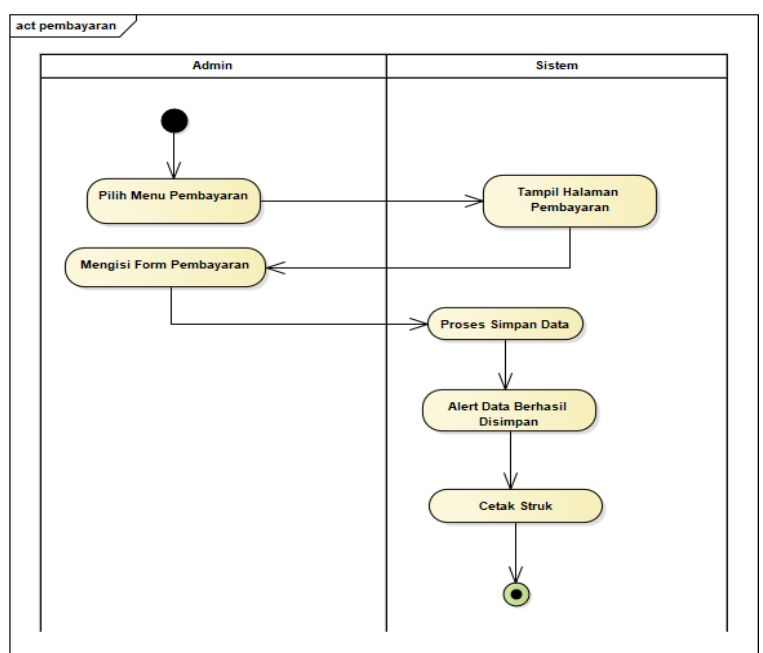

Gambar 4. Activity Diagram Proses Pembayaran Administrasi 


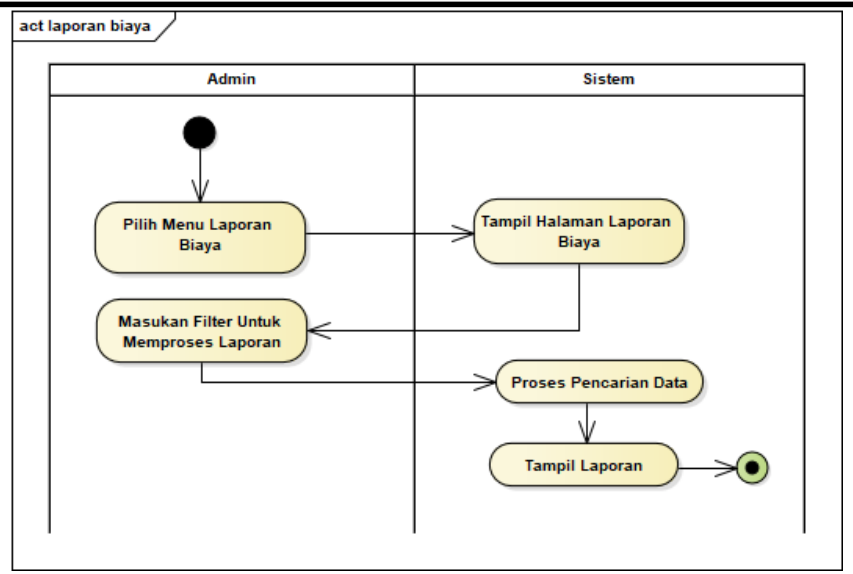

Gambar 5. Activity Diagram Laporan Biaya

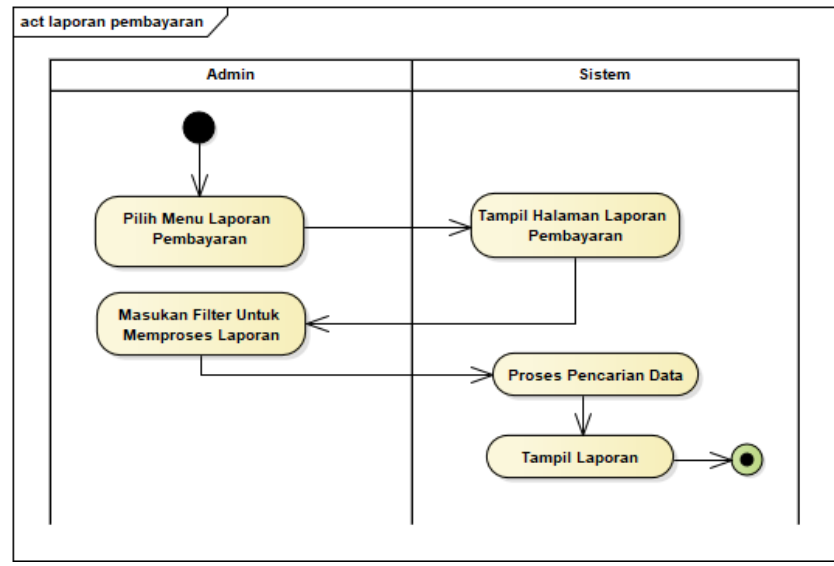

Gambar 6. Activity Diagram Laporan Pembayaran

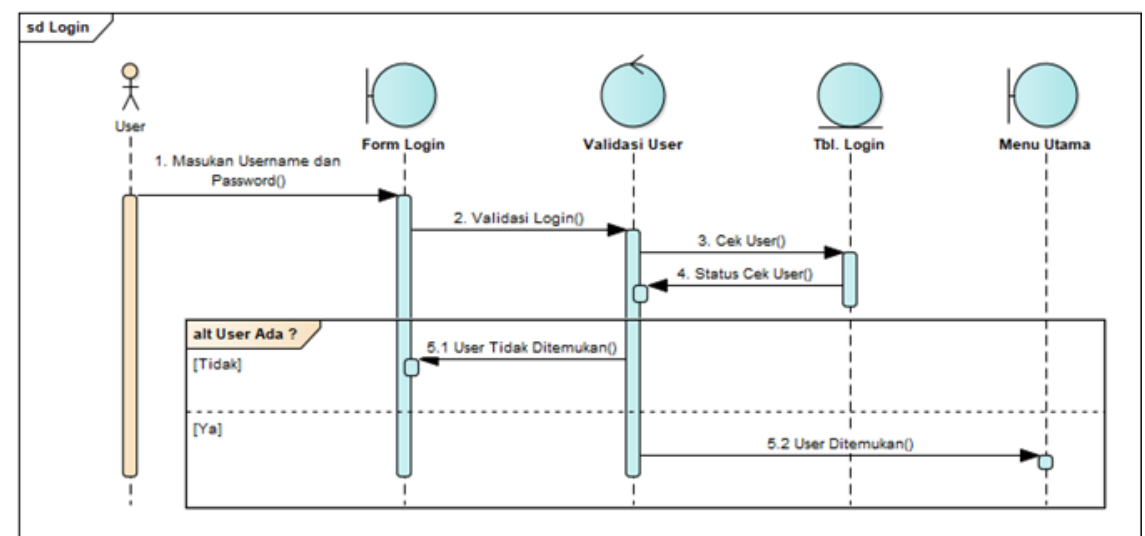

Gambar 7. Sequence Diagram Login 


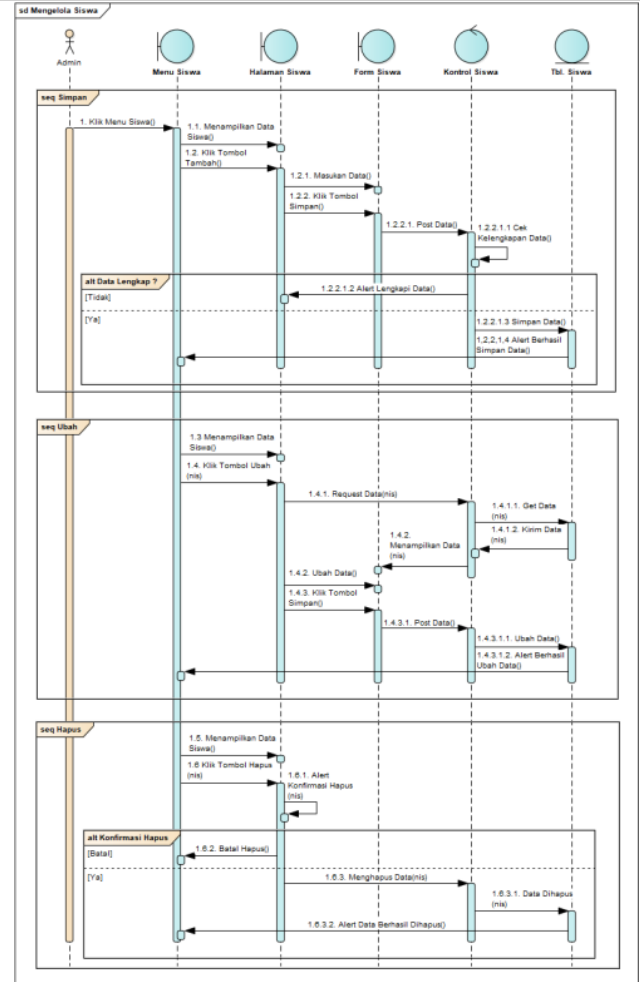

Gambar 9. Sequence Diagram Laporan Biaya

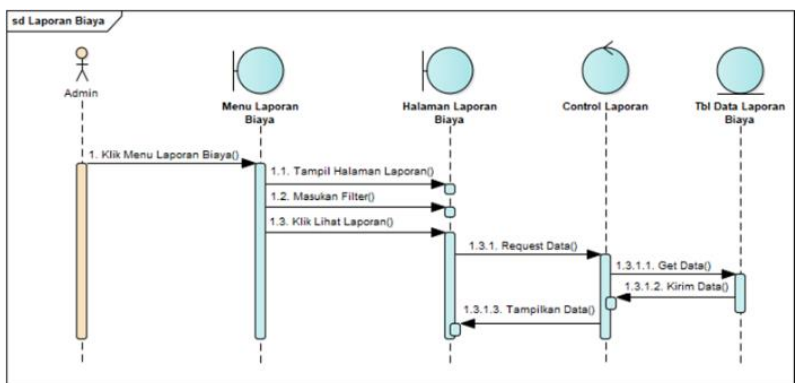

Gambar 8. Sequence Diagram Mengelola Data Siswa

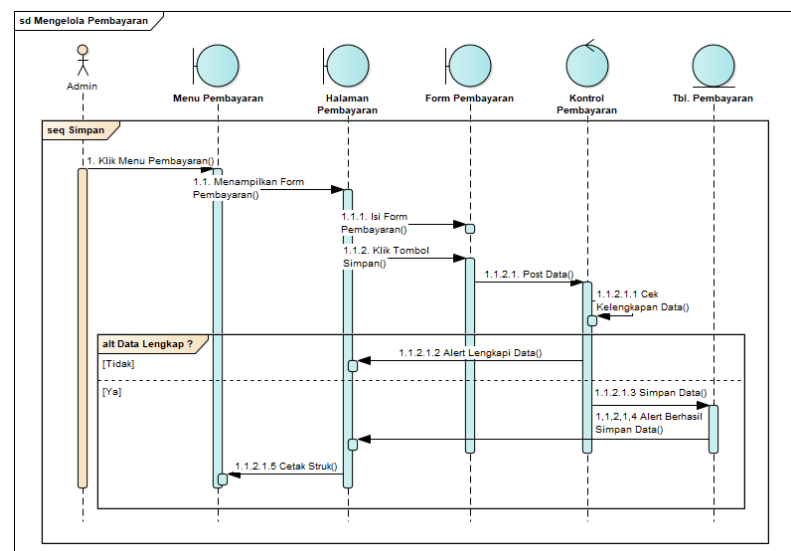

Gambar 8. Sequence Diagram Proses Pembayaran Administrasi 


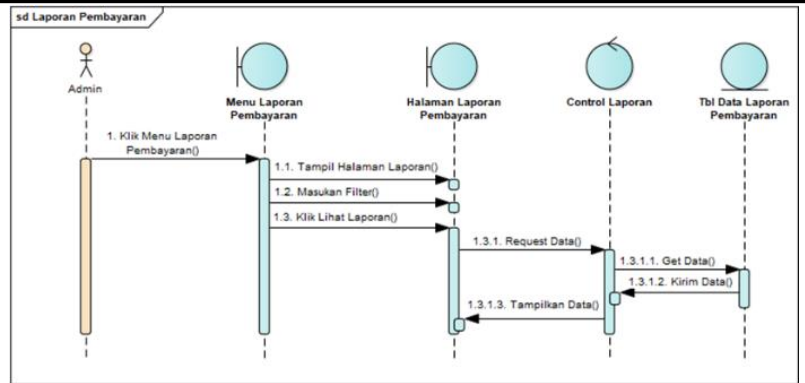

Gambar 9. Sequence Diagram Laporan Pembayaran

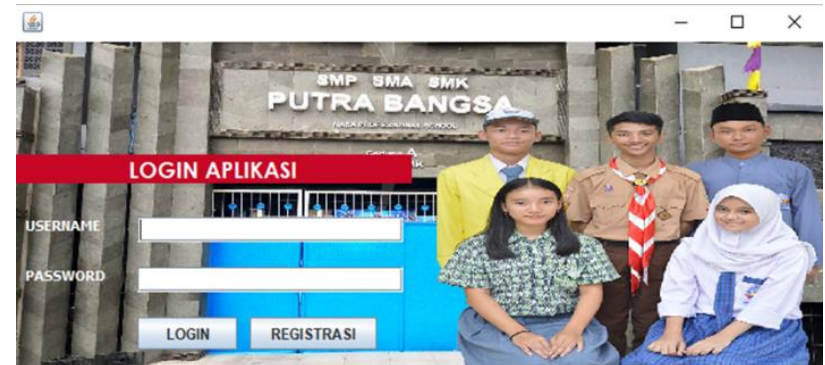

Gambar 10. Tampilan Layar Login

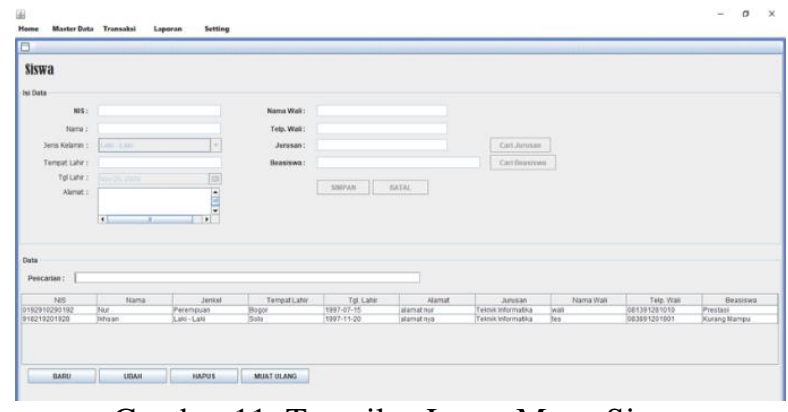

Gambar 11. Tampilan Layar Menu Siswa

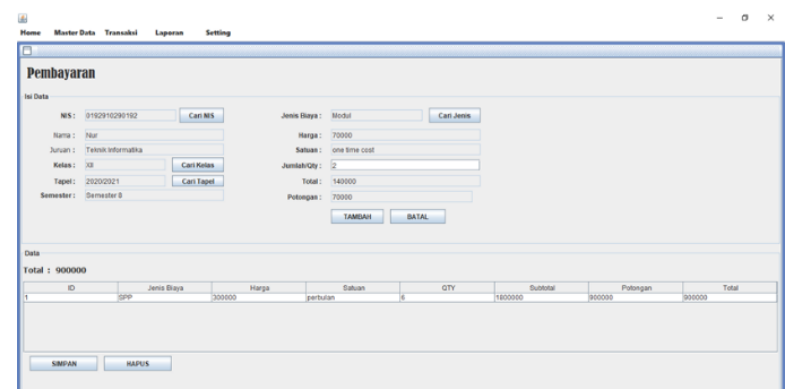

Gambar 12. Tampilan Layar Menu Pembayaran 


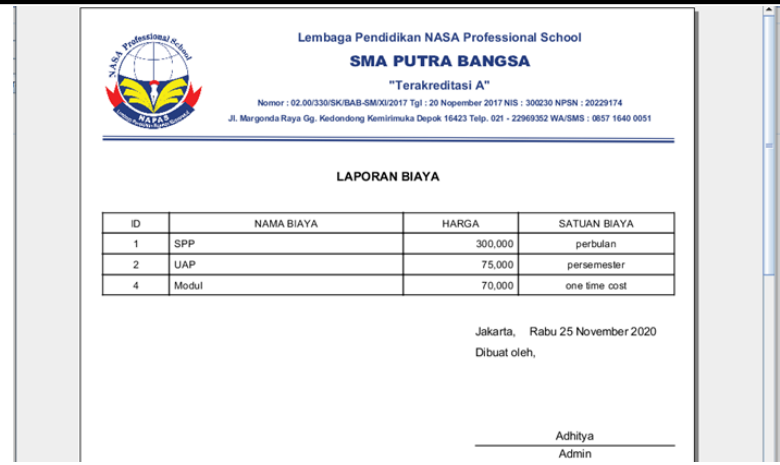

Gambar 13. Tampilan Layar Hasil Laporan Biaya

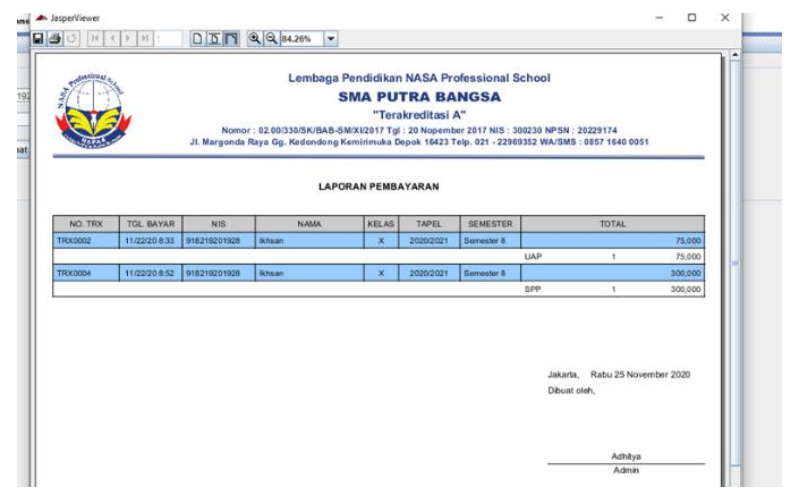

Gambar 14. Tampilan Layar Hasil Laporan Pembayaran

\section{Kesimpulan}

Aplikasi Pembayaran SPP pada SMA Putra Bangsa di Depok yang telah dibuat dan disusun sampai saat ini, seluruh kegiatan yang berhubungan dengan pendataan dan pelaporan pembayaran SPP dilakukan tidak lagi dengan cara manual, tetapi sudah terkomputerisasi dan terintegrasi dengan database.

\section{Daftar Pustaka}

[1] Abdul Kadir. 2011. Faktor-Faktor yang Berpengaruh Terhadap Ketepatan Waktu Pelaporan Keuangan Studi Empiris Pada Perusahaan Manufaktur di Bursa Efek Jakarta. Jurnal Manajemen dan Akuntansi. Vol 12 No. 1 h. 1-12.

[2] Abdurahman, Hasan dan Asep Ririh Riswaya. 2014. Aplikasi Pembayaran Secara Kredit Pada Bank Yudha Bahakti. Jurnal Computech \& Bisnis. 8(2), 61-69.

[3] Chan, Kah Sing. 2004. Electronic Commerce and Supply Chain Management. 2nd edition. Thomas Learning Asia,Singapore.

[4] Harumy, T. H. F., Julham Sitorus, M. L. 2018. Sistem Informasi Absensi Pada PT. Cospar Sentosa Jaya Menggunakan Bahasa Pemrograman Java. Jurnal Teknik Informatika. 5 (1). 63-70.

[5] Heriyanto, Y., Oktavianis, N., \& Informatika, M. 2019. Perancangan Sistem Informasi Pembayaran SPP pada SMK Negeri 04 Pekanbaru Berbasis Desktop. Jurnal Intra Tech 3(1), 10-15.

[6] M. Munawir et al., "Penerapan Sistem Informasi Pendataan Penerima Dana Program Keluarga Harapan pada Gampong Beurawe Kecamatan Kuta Alam berbasis Web GIS," J. Serambi Eng., vol. 6, no. 3, 2021.

[7] Z. Zulfan, B. Bahagia, H. Ahmadian, and D. Satria, "Sistem Informasi Data Korban Kebencanaan Berbasis Web," in Prosiding Seminar Nasional USM, 2017, vol. 1, no. 1.

[8] S. Shopalazuli, B. Baihaqi, and E. Erdiwansyah, "Sistem Informasi Pengambilan Keputusan Penerima Rehab Rumah Menggunakan Metode Weighted Sum Model (WSM) Pada Desa Bira Lhok Kecamatan Montasik," J. Nas. Komputasi dan Teknol. Inf., vol. 4, no. 6, pp. 405-414, 2021. 